\title{
Szeklers' Aspirations for Autonomy: Unconstitutionality or Lack of Political Will?
}

\author{
Szilvia VARGA \\ Babeş-Bolyai University, Cluj-Napoca, PhD Student \\ Doctoral School of Communication, Public Relations and Advertising \\ e-mail: szilvia.varga@ubbcluj.ro \\ A Review of the Volume \\ Attila Dabis: Misbeliefs about Autonomy. The \\ Constitutionality of the Autonomy of Szeklerland ${ }^{1}$
}

Attila Dabis is a political scientist, the Foreign Affairs Commissioner of the Szekler National Council and the International Coordinator of the Institute for the Protection of Minority Rights. Personal motivations undoubtedly contributed to the writing of his book, which is why, although the publisher categorizes the volume as history and political science, emotions are present to some extent, and the reader might feel a frustration that is similar to what the Szeklers have experienced in many cases. The author also reports on his own experiences when he mentions that he was not allowed to cross the Hungarian-Romanian border to attend the annual Szekler Freedom Day in 2018.

In the introduction, the author defines the concept of autonomy as follows: 'Generally, autonomy in minority rights-related literature refers to self-government of a group or territory within a state and can be divided, most simplistically, into territorial and personal autonomy. (...) While the former is based on the whole population of a territorial unit, the latter is based on the members of a specific minority' (p. 22).

For the Szeklers, the goal is to achieve territorial autonomy. However, the Draft Law on the Autonomous Status of Szeklerland (DL) has already been rejected four times (2004, 2005, 2018, 2020) by Romanian decision makers, arguing that such a DL is unconstitutional as it endangers the sovereignty, unity, and indivisibility of the state. As the title suggests, the primary purpose of the book is to deconstruct misbeliefs and misconceptions about autonomy and to dispel the 'constitutional myth', which is perceived as an argument against Szekler autonomy by the Romanian majority.

1 Attila Dabis. 2021. Misbeliefs about Autonomy. Berlin: Peter Lang Verlag, p. 186, ISBN 9783631855805. 
On the one hand, the text is a retrospection outlining the events and important historical moments that contributed to the spread of this myth and, on the other hand, an analysis of the Romanian Constitution, the DL, and the decisions relating to the latter. As a conclusion, the author outlines feasible policy implications that may lead to the achievement of the Szekler (territorial) autonomy.

The book is well-structured, and it consists of five chapters as follows: (1) Introduction, (2) Autonomy and the Constitution of a Nation State, (3) Deconstructing the Constitutional Barrier, (4) Policy Implications, and (5) Conclusions. These are divided into subchapters, thus helping the reader along the way to learn the history and situation of the Szeklers, to form a general picture of autonomy, and to understand the arguments presented against the misbeliefs about autonomy.

The introduction may seem unusually long at first glance (61 pages). Nevertheless, this chapter allows those who have previously been completely unfamiliar with the debate over Szekler autonomy to explore the subject. In this section, the author defines several concepts (different forms of autonomy, self-government, home rule, self-rule, devolution, federalism, etc.) and then places the topic and the problem of autonomy rejection into a theoretical and methodological framework. The historical perspective focuses on the events, declarations, and treaties that contributed to the formation of today's borders and ethnic composition of Romania, the Hungarian minority's aspirations towards autonomy, and the country's political culture.

Part of the problem that Szeklerland (or Székely Land - another name used in English) is not recognized as an autonomous administrative unit is that Romania often appears internationally as a role model with regard to the discourse on national minorities. However, practice shows the opposite. The author presents the two rounds of evaluation (in 2012 and in 2017) of the Romanian undertakings of The European Charter for Regional or Minority Languages (see pp. 44-50) - this is one of the most important parts of the volume. The evaluations show that Romania fulfils only 14 out of the 61 undertakings, the most problematic part being the use of the Hungarian language by administrative authorities and public services.

The first chapter also covers the problem of religious and economic discrimination and the constraints on the use of Hungarian/Szekler symbols. It also highlights cases showing that the authorities use a double standard depending on whether, for example, a demonstration is being organized by the majority (Romanians) or the minority population (Hungarians/Szeklers). According to Dabis, this double standard stems (also) from the fact that there are often grey areas in the law (such as the usage of flags) that are deliberately misinterpreted. At the end of the first chapter, the author's position is already outlined: the obstacle to the pursuit of autonomy is not the law but the lack of political will.

The second chapter reviews the previous constitutions as well as the current one, the articles of which are presented by the decision makers as arguments against Szekler autonomy: 'Article 1 (1) Romania is a sovereign, independent, unitary and 
indivisible National State'2 (p. 27). The dominance of the majority has already been outlined in previous constitutions that did not grant citizenship to non-Christians - this perception has been inherited by today's Romanian society, which in this case would not deprive the minority of its citizenship, but it simply considers territorial autonomy unacceptable. It should be added, however, that the current constitution only rejects the notion of territorial autonomy but accepts personal autonomy, autonomy of religious cults, functional autonomy of universities, and local autonomy of territorial administrative units.

The rest of the chapter and the next one ('Deconstructing the Constitutional Barrier') are worth reading in parallel because Dabis is in fact challenging the arguments against Szekler territorial autonomy. Owing to the structure, the arguments and counter-arguments can be easily followed, which are divided into two major parts, and one can also read the analysis of Opinion No. 405/2004 and of Decision No. 80/2014 of the Constitutional Court of Romania. The study reveals the following substantive and procedural objections to Szekler autonomy and the DL: (1) the DL wants to create another entity besides the nation-state; (2) this issue is a national and not an international matter; (3) it violates the principle of equality between citizens; (4) it threatens the unity, indivisibility, and sovereignty of Romania; (5) the use of Hungarian national symbols is also unconstitutional; (6) the Hungarian and Romanian languages become equal; (7) the Romanian Constitution only recognizes the following administrative units: communes, towns, counties; the autonomy presupposes the creation of a new administrative unit; (8) referring to the Administrative Law 215/2001, they complain that a referendum should have taken place.

The author concludes in his analysis that the argument of unconstitutionality is not valid in either case since the establishment of Szeklerland as an autonomous region 'would not result in the creation of a separate state entity parallel with the Romanian state' (p. 105), the borders of the country would not change, and the Szeklers would remain Romanian citizens - and citizens must be guaranteed equal rights without discrimination. The use of Hungarian and Szekler symbols and the use of the Hungarian language are not part of a zero-sum game and do not imply the abolition of Romanian symbols in the territory; the Romanian language would not cease to be an official language. Furthermore, Dabis highlights another problem related to minority rights: 'if a national minority cannot use its symbols, not even in areas where it represents the overwhelming majority, that is equivalent to denying the right of national minorities to identity' (p. 120).

The reader can also learn about how other countries deal with the issue of autonomy, which can be a starting point for solving the 'Szekler problem'. The fourth chapter ('Policy Implications') is actually a set of recommendations formulated for the following political actors: the Romanian State, the minority community, the

2 The original article in Romanian is as follows: „România este stat național, suveran şi independent, unitar şi indivizibil.” 
kin-state, and the international community. In formulating these proposals, the conclusions of Cunningham, ${ }^{3}$ Ghai and Woodman, ${ }^{4}$ Lapidoth, ${ }^{5}$ and Shaykhutdinov ${ }^{6}$ are important points of reference. They point out that the implementation of autonomy is positively influenced if the citizens belonging to a given minority are concentrated in a certain area within the country, there is a consensus within the minority group, there is an international mediator, the country has a democratic history and respects the rule of law, or the country is in some kind of crisis. In his book, Dabis proposes two solutions for the Romanian state: one requires the amendment of the Constitution or the adoption of a new one, resulting in a federation or a regionalized state, and the other one simply assumes a different interpretation of the Constitution. The minority group should work on domestic trust-building together with the majority, and the most influential minority party must also take a stand on the issue on an ongoing basis. Furthermore, it is necessary for the kin-state to maintain good neighbourly relations with Romania. Besides this, the international community can also play a role in the positive development of the Szekler autonomy (see the example of the Åland Islands).

All in all, Dabis concludes that the Constitution does not provide a real legal barrier to the creation of an autonomous administrative unit, and the rejection of autonomy stems from a lack of political will, as decision makers see this solution as a threat to national security. Citing the words of the author, 'if one reads the Romanian constitution without an ethnocentric mindset and in line with international documents ratified by Romania, it is very much possible to adopt an interpretation of the constitution that is open to accommodate minority claims on regional powersharing' (p. 158). Overall, the author has made a real effort to deconstruct the 'constitutional myth', and the book fills a gap by offering a plan to achieve the goal. The volume is highly recommended to decision makers, previously listed political actors, scholars dedicated to political science, history, and law, and to any 'simple' citizen who is willing to read the book with an open mind and is able to leave the Romanian majority approach behind.

3 See: Cunningham, Kathleen Gallagher. 2007. Divided and Conquered: Why States and SelfDetermination Groups Fail in Bargaining over Autonomy. San Diego: University of California Electronic Theses and Dissertations.

4 See: Ghai, Yash-Woodman, Sophia. 2013. Comparative Perspectives on Institutional Frameworks for Autonomy. In: Ghai, Yash-Woodman, Sophia (eds), Practising Self-Government. A Comparative Study of Autonomous Regions. Cambridge: Cambridge University Press. 449486.

5 See: Lapidoth, Ruth. 1997. Autonomy - Flexible Solutions to Ethnic Conflicts. Washington D.C.: US Institute of Peace Press.

6 See: Shaykhutdinov, Renat. 2010. Give Peace a Chance: Nonviolent Protest and the Creation of Territorial Autonomy Arrangements. Journal of Peace Research 47(2): 179-191. 